\title{
A World Class Order Picking Methodology: An Empirical Validation
}

\author{
Claudia Chackelson ${ }^{1, *}$, Ander Errasti ${ }^{1}$, and Martín Tanco ${ }^{2}$ \\ ${ }^{1}$ Tecnun - University of Navarra, Manuel Lardizabal 13, 20018 San Sebastian, Spain \\ cchackelson@tecnun.es, aerrasti@tecnun.es \\ ${ }^{2}$ University of Montevideo, Ponce 1307, 11300 Montevideo, Uruguay \\ mtanco@um.edu.uy
}

\begin{abstract}
Order picking is the process of retrieving products from storage in response to a specific customer order. Although this process' design has significant impact on warehouse global performance, a practical-oriented design procedure is still lacking in literature. This paper presents a novel order picking system design methodology based on Design for Six Sigma approach, that aims to assist designers making decisions by suggesting the most effective operational and organizational policies and the equipment needed in order to fulfill customer's orders. A case research in a home appliances manufacturer is presented in order to demonstrate the effectiveness of this approach.
\end{abstract}

Keywords: order picking process, design methodology, design for six sigma, case research.

\section{Introduction}

Picking is the process of retrieving products from storage in response to a specific customer order. It has been identified as a key warehouse activity due to its impact on operational costs and service level. An appropriate design can also directly improve global performance (De Koster et al. 2007). In addition, according to Rushton et al. (2006) and Errasti et al. (2010) the design of this process has become particularly important and complex due to recent trends in distribution centers: an increasing number of make to stock items in the warehouse, a reduction in delivery times to 2448 hours, an increasing level of customization in orders, or a reduction in the number of minimum delivery units.

It has been pointed out that most of the research related to order picking focuses on a specific situation or design issue (De Koster et al. 2007, Manzini et al. 2007, Ekren et al. 2009). However, extrapolating methods developed for one particular situation to a different situation is not that simple. Even though some authors have identified the elements and alternatives (Goetschalckx and Ashayeri 1989) and other authors have identified the tasks (Yoon and Sharp 1996), a general design procedure for the order picking process is still lacking in the literature (De Koster et al. 2007).

\footnotetext{
* Corresponding author.
} 
$\mathrm{Gu}$ et al. (2010) state that it would be worthwhile to carry out research that characterizes order picking alternatives in such a way that they could support design process. Moreover, these authors conclude that both applied design models and practical cases that show the value of bringing academic research results to real situations are necessary. More case studies and computational tools for warehouse design and operation will help bridge the significant gap between academic research and practical application.

We propose a novel order picking system design methodology that aims to fill the following gaps: (1) the lack of a flexible order picking design framework, (2) the misuse of tools and techniques that allow the modeling and simulation of operative processes in the design or redesign phase of a operative process to be incorporated and (3) the scarcity of empirical investigations that allow the applicability of new procedures and technologies to be evaluated.

\section{State of the Art}

Yoon and Sharp (1996) outlined a procedure for analyzing and designing order picking systems with three steps: a) input stage, b) selection stage, and c) evaluation stage. After this last stage, different subsystems are compared, and overall performance is evaluated. These authors only suggested that these steps need to be taken; however they did not specify how these steps could be performed, nor how to select the most suitable picking configuration according to the complexity of the process. In this context, Baker and Canessa (2009) highlight that there is no consensus on the exact nature of the tools and techniques to be used for each design step. The same authors also state that great reliance is put on the knowledge of the designer in deducing which tools need to be used, and final design decisions are made based on intuition, experience and judgment.

Dallari et al. (2009) improved Yoon and Sharp (1996) design procedure with the development of a new taxonomy based on the analysis of 68 warehouses located in Italy. We believe that this has been an important step into bridging the existing gap, but a major degree of detail regarding to order picking alternatives is still needed in order to support effectively the design process.

We propose a novel order picking system design methodology for use in warehouses and distribution centers. This procedure assist designers making decisions, by suggesting the most effective operational and organizational policies, as well as the equipment needed in order to fulfill orders considering their typologies.

This procedure is based on the Design for Six Sigma (DFSS) approach (Yang and El-Haik 2003; Brue 2003). It has been developed for achieving Six Sigma process capabilities on the design side. In design, opportunities are virtually unlimited since most of the costs of a product are determined in the design stage (Montgomery 2005). We decided to adapt DFSS due to its focus on design or redesign products/processes right the first time, by integrating tools and methods that look for robustness. The DFSS approach with four stages ICOV (Identification of requirements, Characterization, Optimization and Verification) was followed, although there are varieties in literature such as DMADV, IDOV, etc. 
Six Sigma is, by definition, analytical and profoundly rooted in statistical analysis. It was defined by Linderman et al (2003) as "an organized and systematic method for strategic process improvement and new product and service development that relies on statistical methods and the scientific method to make dramatic reductions in customer defined defect rates". A key difference between Six Sigma and other approaches is the integration of a highly disciplined process (such as IDOV) with one that is very quantitative and data oriented. This is a winning combination as evidenced by the results of the companies that have used it (Hahn 2005).

DFSS is one of the drivers of research and application of experimental design techniques. So is the expanding deployment of Six Sigma in general, where it is broadly recognized that Design of Experiments is the most powerful and important of the Six Sigma tools (Montgomery 2006). Therefore, the order picking system design methodology developed incorporates elements from the Design of Experiments (DoE) (Box et al. 2005) and the Discrete Event Simulation technique (Banks 2010) when selecting the most suitable design strategy from those suggested in a previous stage. A simulation model is developed, considering the external and internal factors that influence picking performance identified by Goetschalckx and Ashayeri (1989) and Frazelle (2002).

\section{Order Picking Design Methodology}

The proposed methodology takes the procedure proposed by Yoon and Sharp (1996) and fit its three steps (Input, Selection, and Evaluation) into a DFSS approach with four stages (Identification of requirements, Characterization, Optimization, and Verification). It also details how each stage is to be performed and what tools and techniques need to be used.

\subsection{Identification of Requirements Step}

According to Frazelle (2002), the factors that have to be considered when categorizing this process are:

- Order type (lines per order, items per line)

- Picking volume complexity (orders/t, lines/t, or items/t)

- Product characteristics (shape, volume, weight) and heterogeneity

- Storage unit vs. order unit

- Number of make to stock items.

The first stage of the proposed methodology takes these factors into account in order to establish the order picking complexity. The characterization is performed employing a priority matrix that assigns a discrete level of complexity: medium, high or extreme picking (Errasti 2011). This matrix has been gauged after a Delphi study carried out among 40 world class companies with different order picking complexities. Table 1 shows the valuation ranges and the weighing that have been given to the five factors previously mentioned. 
Table 1. Priority matrix for determining order picking complexity level

\begin{tabular}{|c|c|c|c|c|}
\hline FACTOR & \multicolumn{3}{|c|}{ Valuation Ranges } & Weighing \\
\hline \multirow{2}{*}{$\begin{array}{l}\text { Picking Volume } \\
\text { (lines/t) }\end{array}$} & Lines $<100$ & $100<$ Lines $<1000$ & $1000<$ Lines & \multirow{2}{*}{3} \\
\hline & 1 & 2 & 3 & \\
\hline \multirow{2}{*}{$\begin{array}{c}\text { Storage unit vs. } \\
\text { order unit }\end{array}$} & Ratio $>75 \%$ & $25 \%<$ Ratio $<75 \%$ & $25 \%>$ Ratio & \multirow{2}{*}{3} \\
\hline & 1 & 2 & 3 & \\
\hline \multirow{2}{*}{$\begin{array}{l}\text { Number of make } \\
\text { to stock items }\end{array}$} & Number $<100$ & $100<$ Number $<1000$ & $1000<$ Number & \multirow{2}{*}{2} \\
\hline & 1 & 2 & 3 & \\
\hline \multirow{2}{*}{$\begin{array}{l}\text { Different order } \\
\text { type }\end{array}$} & Number $=1$ & Number $=2$ & Number $>3$ & \multirow{2}{*}{1} \\
\hline & 1 & 2 & 3 & \\
\hline \multirow{2}{*}{$\begin{array}{l}\text { Different Prod- } \\
\text { uct characteris- } \\
\text { tics }\end{array}$} & Number $=1$ & Number $=2$ & Number $>3$ & \multirow{2}{*}{1} \\
\hline & 1 & 2 & 3 & \\
\hline
\end{tabular}

The order picking complexity level is determined by calculating a value obtained after multiplying the valuation range and its corresponding weighing (see Table 2).

Table 2. Order picking complexity levels

\begin{tabular}{|c|c|}
\hline Order Picking Complexity Level & Value \\
\hline Extreme Picking & Value $>=25$ \\
\hline High Picking & $20<=$ Value $<25$ \\
\hline Medium Picking & $10<=$ Value $<20$ \\
\hline
\end{tabular}

Once this characterization has been carried out, a group of possible designs are suggested in the following step.

\subsection{Characterization of the Design Stage}

This second step aims to delimit the large variety of solutions and parameters considered according to the process complexity, reducing the time required to find the most appropriate solution in the next phase. With this aim in mind, several charts of alternatives are proposed. Order picking processes design is highly complex owing to the high number of existing possibilities (Baker and Canessa 2009), thus this is an important contribution because it helps designers choose from among the most appropriate alternatives. The suggested designs are the result of a Delphi study carried out among 40 world class companies with different order picking complexities. In this phase, the designer needs to select the two or three designs they consider the most suitable according to their experience.

The alternatives suggested include the classic factors that influence picking performance identified by Goetschalckx and Ashayeri (1989): mechanization level (automated, semi-automated, mechanized or manual), order realize mode (wavepicking or continuous), zoning (one zone or multi-zone), batching (pick-by-order or pick-by-article, and pick-and-sort or sort-while-pick), storage (random, class-based, 
family grouping, or dedicated), and routing (heuristic or optimal), but also incorporate the new operational or technological options implemented by companies nowadays. Figure 1 shows the huge range of possibilities that warehouse managers face when designing order picking process.

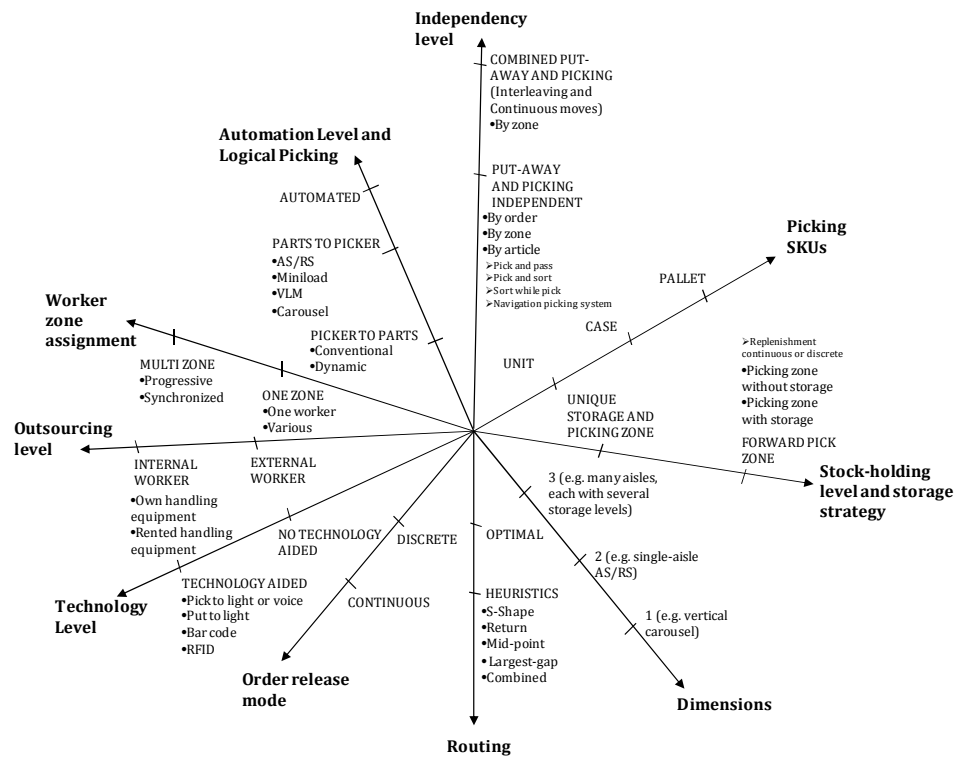

Fig. 1. Order picking design possibilities

Figure 2 exemplifies the alternatives proposed in view of the different order picking complexity levels.

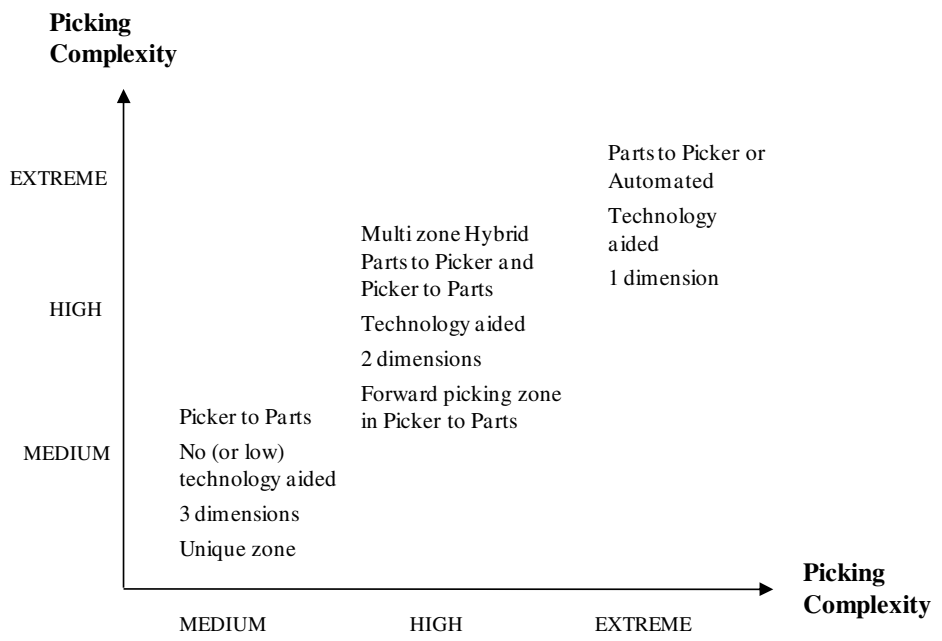

Fig. 2. General alternative chart 
Three new charts with a higher degree of detailed of handling systems and equipments have been built in order to extend the information shown in Figure 2 (see Figure 3). Further information could be found in Errasti (2011).
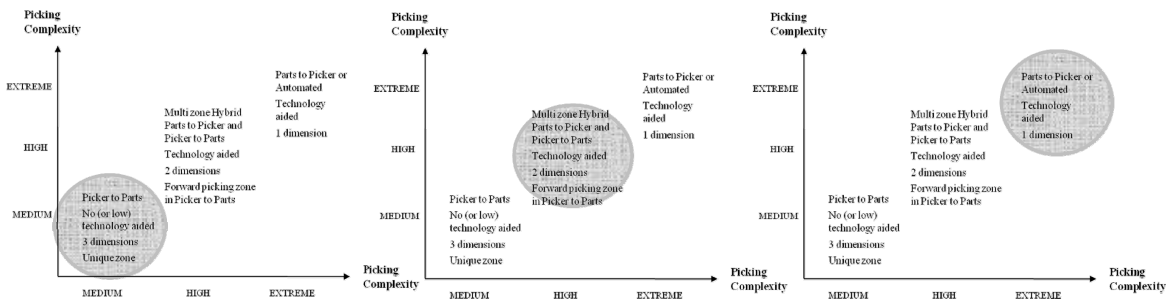

Fig. 3. Alternative charts according to order picking complexity level

\subsection{Optimization of the Design Stage}

In this step the most suitable alternative is selected. This selection is performed according to Frazelle's (2002) Key Performance Indicators KPIs (cost, utilization, productivity, quality and time), and a priority matrix is suggested in order to weight those metrics according to the business's characteristics.

The development of a Discrete Events Simulation model is suggested in order to compare the chosen alternatives during Characterization of the Design Stage. Chackelson et al. (2011) had verified the effectiveness of combining those techniques.

DoE is proposed with the aim of detecting interrelation between factors, and in order to be aware of how operational and organizational policies are affected by different demand characteristics. In other words, based on DoE approach, the methodology proposed in this paper involves a series of tests in which changes are made to the input variables of the process or system in order to observe and identify the impact of these changes on the output response(s) (Montgomery 2008).

The experiments are carried out in the simulation model, which allows for the comparison of the maximum number of input and output variables, identifying the most significant effects and discarding the variables with less influence on performance. This technique can be adapted to a variety of situations as well as to fluctuating business needs.

It important to highlight that warehouse processes design is highly complex and it may not be possible to identify what is the optimum solution, owing to the high number of existing possibilities (Baker and Canessa 2009).

\subsection{Verification Stage}

A Verification Stage is needed in order to corroborate that the simulation computer program performs as intended and that it is also an accurate representation of the system under study. The obtained results can be used to support decision making process only after the simulation model has been subjected to this verification and validation process (Law and Kelton 1991).

With this aim in mind, different techniques could be used such as Animation or the Comparison of Simulated and the Real data (Kleijnen 1995, Sargent 1996). 


\section{Case Research}

In this study, we use a Case research carried out in the small appliances warehousing order picking process of a home appliances manufacturer in order to test the utility of the proposed methodology. The whole design procedure has been followed during the design of the order picking process, and at the moment the implementation is taking place successfully.

A description of the results obtained after the four steps of the order picking design methodology are described in this section.

Table 3. Case research priority matrix

\begin{tabular}{|c|c|c|c|c|}
\hline FACTOR & \multicolumn{3}{|c|}{ Valuation Ranges } & Weighing \\
\hline \multirow{2}{*}{$\begin{array}{l}\text { Picking Volume } \\
\text { (lines/t) }\end{array}$} & Lines $<100$ & $100<$ Lines $<1000$ & $1000<$ Lines & \multirow{2}{*}{3} \\
\hline & 1 & 2 & 3 & \\
\hline \multirow{2}{*}{$\begin{array}{l}\text { Storage unit vs. } \\
\text { order unit }\end{array}$} & Ratio $>75 \%$ & $25 \%<$ Ratio $<75 \%$ & $25 \%>$ Ratio & \multirow{2}{*}{3} \\
\hline & 1 & 2 & 3 & \\
\hline \multirow{2}{*}{$\begin{array}{l}\text { Number of make } \\
\text { to stock items }\end{array}$} & Number $<100$ & $100<$ Number $<1000$ & $1000<$ Number & \multirow{2}{*}{2} \\
\hline & 1 & 2 & 3 & \\
\hline \multirow{2}{*}{$\begin{array}{l}\text { Different order } \\
\text { type }\end{array}$} & Number=1 & Number $=2$ & Number $>3$ & \multirow{2}{*}{1} \\
\hline & 1 & 2 & 3 & \\
\hline \multirow{2}{*}{$\begin{array}{c}\text { Different } \\
\text { Product } \\
\text { characteristics }\end{array}$} & Number=1 & Number $=2$ & Number $>3$ & \multirow[b]{2}{*}{1} \\
\hline & 1 & 2 & 3 & \\
\hline
\end{tabular}

According to Table 3, it is a Medium Picking situation because the value that determines the order picking complexity level is $19=2 \times 3+2 \times 3+2 \times 2+2 \times 1+1 \times 1$. Figure 4 shows the chart of alternatives that corresponds to that complexity level.
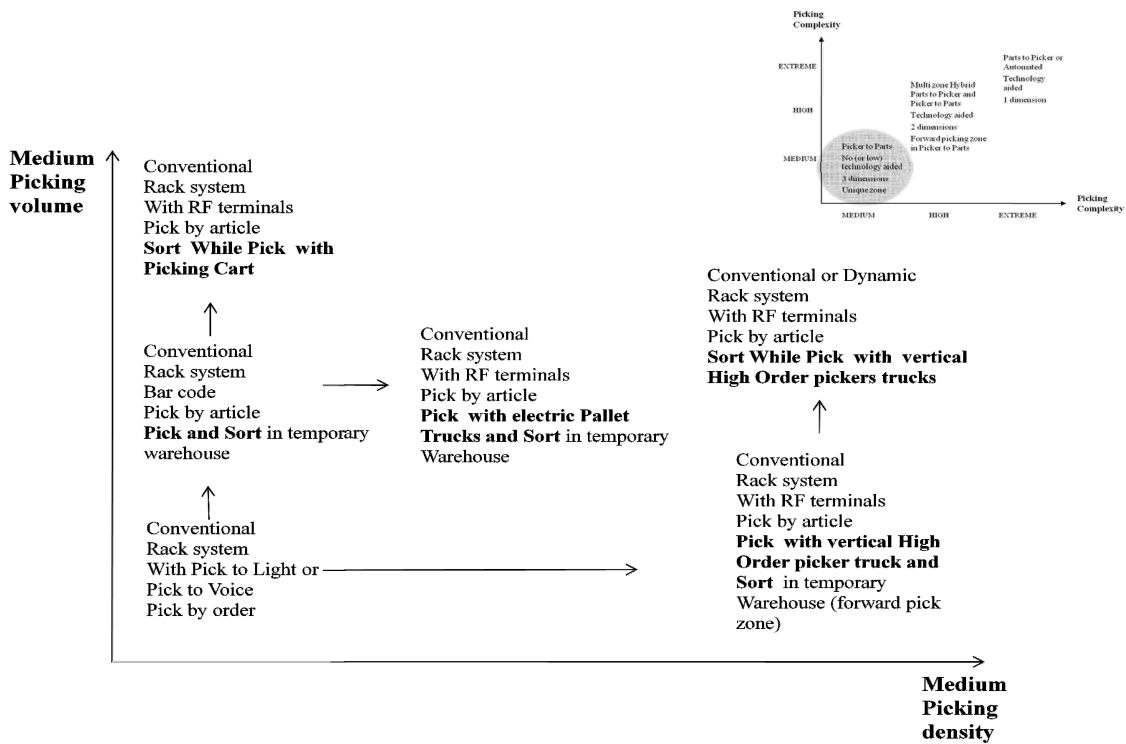

Conventional or Dynamic

Rack system

With RF terminals

Pick by article

Pick with electric Pallet

Prucks and Sort in temporary

Pick with vertical High

Order picker truck and

ort in temporary

Varehouse (forward pick

lium

density

Fig. 4. Medium picking alternative chart 
The warehouse designer selected a conventional rack system with electric pallet trucks. A discrete event simulation model using AnyLogic 6.6.0 University was built in order to analyze the following picking operational alternatives:

- Class-based storage strategy vs. family grouping

- Within-aisle vs. across-aisle storage implementation strategy

- Pick by-article vs. pick by-order.

The criteria selected in order to determine the most suitable alternative was the travel distance (m/day). The following table shows the comparison between the analyzed possibilities:

Table 4.

\begin{tabular}{lllll}
\hline Storage strategy & Implementation & policy Batching & Travel distance & Improvement \\
\hline Family grouping & - & By-order & $46.191 \mathrm{~m} / \mathrm{day}^{2}$ & - \\
ABC class-based & Within-aisle storage & By-order & $45.570 \mathrm{~m} / \mathrm{day}^{2}$ & $1,4 \%$ \\
ABC class-based & Across-aisle storage & By-order & $40.561 \mathrm{~m} / \mathrm{day}^{2}$ & $14 \%$ \\
ABC class-based & Across-aisle storage & Combined $^{1}$ & $39.724 \mathrm{~m} /$ day $^{2}$ & $16 \%$ \\
\hline \hline
\end{tabular}

${ }^{1}$ Combined: A-items by article and $\mathrm{B}$ and $\mathrm{C}$ items by order

The final design included an $\mathrm{ABC}$ class-based storage policy across-aisle, combined with a mix picking policy (A-items by article and $\mathrm{B}$ and $\mathrm{C}$ items by order) in a conventional rack system with electric pallet trucks.

\section{Conclusion and Future Work}

The present work is focused on order picking design. A novel methodology is proposed with the aim of filling: (1) the lack of a flexible order picking design framework, (2) the misuse of tools and techniques that allow the modeling and simulation of operative processes in the design or redesign phase of a operative process to be incorporated and (3) the scarcity of empirical investigations that allow the applicability of new procedures and technologies. Based on the Design for Six Sigma approach, this procedure assists the designer suggesting the most suitable picking alternatives according to the process complexity level (medium, high or extreme). The preferred alternatives are suggested to be compared according to according to Frazelle's (2002) Key Performance Indicators KPIs (cost, utilization, productivity, quality and time), and utilizing a discrete event simulation model. A Design of Experiments approach is also proposed with the aim of detecting interrelation between factors, and in order to be aware of how operational and organizational policies are affected by different demand characteristics.

A case research was carried out, where the warehouse designer admits to being satisfied with the support this methodology has provided him, and highlighted the power of visualizing the possible designs in a simulation model when selecting the final configuration.

Many authors state that a comprehensive and science-based methodology for the overall design of warehouses does not appear to exist (Baker and Canessa 2009, 
$\mathrm{Gu}$ et al 2010). This important concept is being taken into account while improving the recommended order picking design approach, while looking at a modular point of view that allows it to be easily incorporated into a generic methodology.

In addition, the proposed methodology only addresses design aspects from a material flow point of view. In future studies, sizing and dimensioning of order picking process from a stock perspective will be included.

\section{References}

1. Baker, P., Canessa, M.: Warehouse design: A structured approach. European Journal of Operational Research 193, 425-436 (2009)

2. Banks, J., Carson, J.S., Nelson, B.L.: Discrete-Event System Simulation. Prentice Hall, United States (2010)

3. Box, G.E.P., Hunter, J.S., Hunter, W.G.: Statistics for experimenters - Design, Innovation and Discover. John Wiley \& Sons (2005)

4. Brue, G., Lausny, R.G.: Design for Six Sigma. McGraw Hill (2003)

5. Chackelson, C., Errasti, A., Cipres, D., Lahoz, F.: Design of a part to picker system. Design of experiments application aided by discrete event simulation. Dyna. 86, 515-522 (2011)

6. De Koster, R., Le-Duc, T., Roodbergen, J.: Design and control of warehouse order picking: A literature review. European Journal of Operational Research 102, 481-501 (2007)

7. Dallari, F., Marchet, G., Melacini, M.: Design of order picking system. International Journal of Advanced Manufacturing Technologies 42, 1-12 (2009)

8. Ekren, B., Heragu, S., Krishnamurthy, A., Malmborg, C.: Simulation based experimental design to identify factors affecting performance of AVS/RS. Computer and Industrial Engineering (2009) (article in press)

9. Errasti, A.: Logística de almacenaje. Diseño y gestión de almacenes y plataformas logísticas. World Class Warehousing. Ediciones Pirámide, España (2011)

10. Errasti, A., Chackelson, C., Arcelus, M.: Estado del arte y retos para la mejora de sistemas de preparación de pedidos en almacenes: Estudio Delphi. Dirección y Organización 40, 78-85 (2010)

11. Frazelle, E.: World-Class Warehousing and Material Handling. McGraw-Hill, New York (2002)

12. Goetschalckx, M., Ashayeri, J.: Classification and design of order picking systems. Logistics World, 99-106 (June 1989)

13. Gu, J., Goetschalckx, M., McGinnis, L.: Research on warehouse design and performance evaluation: A comprehensive review. European Journal of Operational Research 203, 539549 (2010)

14. Hahn, G.J.: Six Sigma: 20 key lessons learned. Quality and Reliability Engineering International 21, 225-233 (2005)

15. Kleijnen, J.P.C.: Verification and validation of simulation models. European Journal of Operational Research 82, 145-162 (1995)

16. Law, A.M., Kelton, W.D.: Simulation Modeling and Analysis. McGraw-Hill, New York (1991)

17. Linderman, K., Schroeder, R., Zaheer, S., Choo, A.: Six Sigma: A goal-theoretic perspective. Journal of Operations Management 21, 193-203 (2003)

18. Manzini, R., Gamberi, M., Persona, A., et al.: Design of a class based storage picker to product order picking system. International Journal of Advanced Manufacturing Technologies 32, 811-821 (2007) 
19. Montgomery, D.C.: Generation III Six Sigma. Quality and Reliability Engineering International 21, 3-4 (2005)

20. Montgomery, D.C.: Designed Experiments in Process improvement. Quality and Reliability Engineering International 22, 863-864 (2006)

21. Montgomery, D.C.: Design and Analysis of Experiments. John Wiley \& Sons (2008)

22. Rushton, A., Croucher, P., Baker, P.: The handbook of logistics and distribution management. Kogan Page Publishers (2006)

23. Sargent, R.G.: Verifying and validating simulation model. In: Proc. of 1996. Winter Simulation Conf., pp. 55-64 (1996)

24. Yang, K., El-Haik, B.: Design for Six Sigma: A roadmap for product development. McGraw-Hill (2003)

25. Yoon, C.S., Sharp, G.P.: A structured procedure for analysis and design of order pick systems. IIE Transactions 28, 379-389 (1996) 